\title{
Fixed Drug Eruption After Ingestion of Naproxen in a Patient Who Tolerated Ibuprofen and Dexketoprofen
}

Reguero Capilla M, De Aramburu Mera T, Ochando Díez-Canseco $\mathrm{M}$, Prados Castaño M

Department of Allergology, University Hospital Virgen del Rocio, Seville, Spain

J Investig Allergol Clin Immunol 2021; Vol. 31(2): 173-175 doi: $10.18176 /$ jiaci.0518

Key words: Fixed drug exanthema. Naproxen. Arylpropionic acid derivatives. NSAIDs.

Palabras clave: Exantema fijo medicamentoso. Naproxeno. Arilpropiónicos. AINE.

Nonsteroidal anti-inflammatory drugs (NSAIDs) are used worldwide because of their analgesic, antiinflammatory, and antipyretic effects. NSAIDs are one of the most frequent causes of drug-induced hypersensitivity reactions, with urticaria and angioedema as the most common manifestations [1]. Patients who present symptoms after the intake of an NSAID do not usually tolerate others from the same chemical group owing to marked cross-reactivity between NSAIDs that are structurally similar $[2,3]$. Controlled oral challenge test with the culprit NSAID is currently the diagnostic gold standard for confirming a case of hypersensitivity to NSAIDs [1-3]. Naproxen is a nonsteroidal anti-inflammatory drug belonging to the arylpropionic acid family and a nonselective COX inhibitor that is used to treat menstrual cramps, inflammatory diseases such as rheumatoid arthritis, and fever. Fixed drug eruption involves the appearance of a well-circumscribed erythematous patch as a consequence of systemic exposure to a drug. It is an allergic reaction to a medicine that characteristically recurs at the same site or sites each time a particular drug is taken. While many drugs cause fixed drug eruption, the condition is frequently associated with antibiotics and NSAIDs such as ibuprofen $[1,2,4]$. In this paper, we report a case of fixed drug eruption that developed several hours after taking naproxen. The patient tolerated other arylpropionic acid derivatives (ibuprofen and dexketoprofen), as confirmed with a controlled oral challenge for each drug.

The patient was a 25-year-old woman with no history of interest other than polycystic ovary syndrome. She was referred to our allergy unit because 10 years previously, she developed an itchy erythematous-violaceous patch on the right side of her neck approximately 4 hours after taking naproxen. No urticaria/angioedema or systemic symptoms were recorded. The eruption resolved in 48 hours without treatment. She has not taken naproxen since then but has subsequently tolerated ibuprofen and dexketoprofen. She also occasionally consumes paracetamol and metamizole without problems.

We performed a series of diagnostic tests, with an interval of at least 1 week between doses, as follows: 
- Patch test with naproxen, ibuprofen, and dexketoprofen, with readings at 48 and 96 hours (preparations were made using petrolatum as a vehicle and at concentrations similar to those suggested in other studies [6]; naproxen $30 \%$, ibuprofen $5 \%-10 \%$, and ketoprofen $1 \%-10 \%$ ). The result was negative.

- Patch-test with naproxen applied to the patient's neck. The control was a petrolatum patch, with readings at 48 and 96 hours. The result was negative.

- Day 1: A single-blind placebo-controlled oral challenge (SBPCOC) with ibuprofen at doses of 50, 100, and $250 \mathrm{mg}$ at intervals of 30,60 , and 120 minutes, and an observational period of 4.5 hours. The result was negative.

- Day 2: SBPCOC with the intake of a single dose of 600 mg of ibuprofen (higher dose than the day before because the patient reported taking $600 \mathrm{mg}$ at home) and an observational period of 4.5 hours. The result was negative.

- SBPCOC with dexketoprofen 6, 6, and $12 \mathrm{mg}$ at intervals of 30,30 , and 120 minutes, respectively, until the therapeutic dose was reached, followed by an observational period of 4 hours. The result was negative.

- SBPCOC with naproxen 50, 150, and $300 \mathrm{mg}$ every 30 minutes, with 240 minutes of observation. The result was positive (itchy erythematous eruption on the side of the neck, with no associated urticaria, angioedema, or systemic symptoms) (Figure).

We established time intervals of 30 to 60 minutes between each DPT because, once sensitized, the reaction appeared

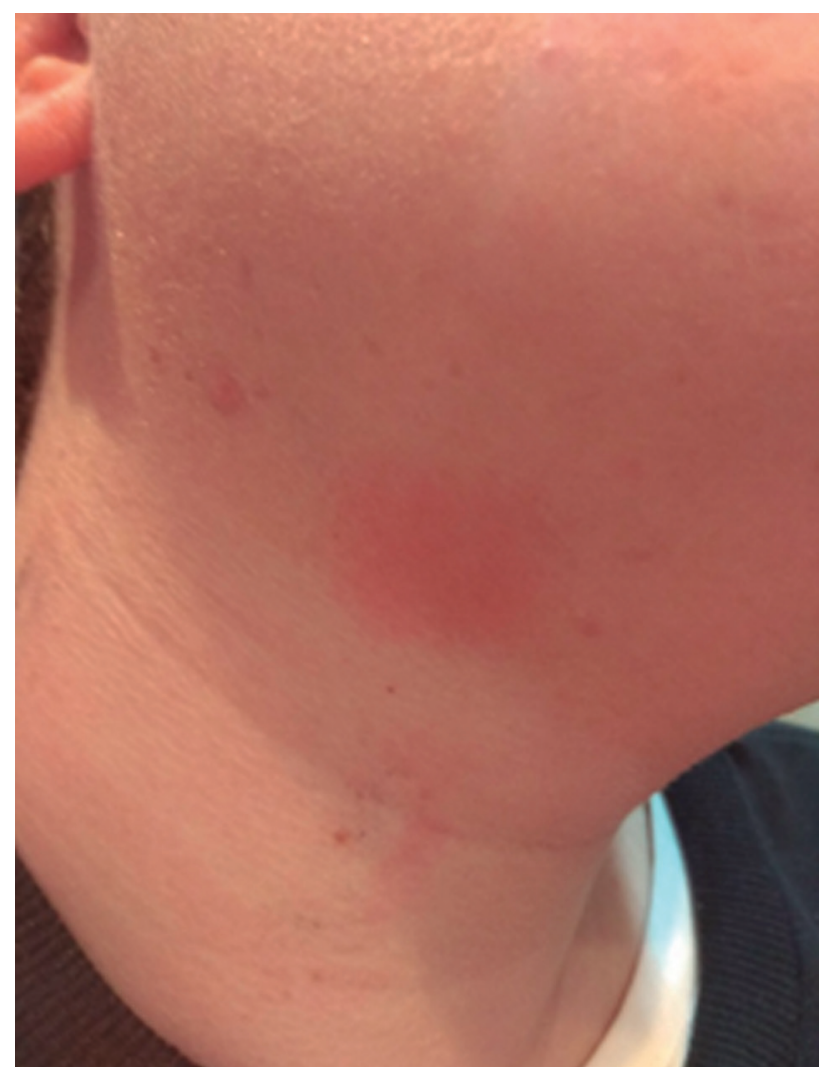

Figure. Fixed drug eruption on the patient's neck after oral challenge testing with naproxen. between 30 minutes and 8 hours after intake, although this interval may be shorter in the case of recurrent contact with the drug [4].

The final diagnosis was fixed drug eruption induced by naproxen.

Recent data show that NSAIDs are the most frequent cause of drug hypersensitivity reactions [5]. The second most frequent cause of these reactions, after pyrazolones [1], is arylpropionic acid derivatives, specifically ibuprofen. The NSAID most commonly associated with fixed drug eruption is ibuprofen.

The patient can be considered to have experienced a single NSAID-induced hypersensitivity reaction because she tolerates NSAIDs from other chemical groups. Patients with immediate reactions to 2 or more NSAIDs that are not structurally related and who tolerate aspirin have been reported, with the result that this phenotype must be taken into account [7]. In the present case, the patient also tolerated another NSAID that is structurally similar to naproxen, the culprit drug. Cases of urticaria and/or angioedema associated with one drug have been described in patients who tolerate others from the same family [2]. However, in this paper, we report a case of fixed drug eruption after administration of an arylpropionic acid derivative (naproxen) in a patient who tolerated other drugs from this family (ibuprofen and dexketoprofen). The time interval between the intake of the NSAID and the appearance of erythema in the present case was about 4 hours.

The usefulness of skin testing has been documented for pyrazolones [8], although few data are available on its utility with arylpropionic acid derivatives because of its poor reliability. Oral challenge remains the gold standard for diagnosing allergy to NSAIDs; it is not indicated in patients with a history of generalized exanthema or when the exanthema involves mucous tissues. In patients without generalized reactions or extended mucous involvement, oral challenge is considered relatively safe and remains the gold standard, thus confirming the affected area and the culprit agent [4]. Fixed drug eruption characteristically reappears at the same location and with a similar extension [9]. In this case, with a small skin area affected, and given the negative result in the patch test and tolerance to ibuprofen and dexketoprofen in the oral challenge, as well as the remarkable cross-reactivity between members of the arylpropionic family, we decided to perform a diagnostic test with naproxen in order to prove the reproducibility of the symptoms. The result was positive (erythematous-violaceous oval lesion on the side of the patient's neck).

We report a case of fixed drug eruption induced by naproxen, with no associated urticaria/angioedema and no cross-reactivity between the same structural groups. Diagnosis was by single-blind placebo-controlled oral challenge. We conclude that arylpropionic acid derivatives may induce fixed drug eruption as a hypersensitivity reaction in patients with good tolerance to other drugs from the same chemical group. While more studies are needed, we would like to emphasize the importance of carrying out tolerance tests with another NSAID within the same group because of the probability of tolerance. Cases should be managed on an individual basis.

\section{Funding}

The authors declare that no funding was received for the present study. 


\section{Conflicts of Interest}

The authors declare that they have no conflicts of interest.

\section{References}

1. Blanca-Lopez N, Perez-Alzate D, Andreu I, Doña I, Agundez JA, Garcla-Martın E, et al. Immediate hypersensitivity reactions to ibuprofen and other arylpropionic acid derivatives. Allergy. 2016;71:1048-56.

2. Ortega N, Doña I, Moreno E, Audicana MT, Barasona MJ, Berges- Gimeno MP, et al. Practical guidelines for diagnosing hypersensitivity reactions to nonsteroidal anti-inflammatory drugs. J Investig Allergol Clin Immunol. 2014;24:308-23.

3. Doña I, Barrionuevo E, Blanca-López N, Torres MJ, Fernández $T D$, Canto G, et al. Trends in hypersensitivity drugs reactions: more drugs, more response patterns, more heterogeneity. J Investig Allergol Clin Immunol. 2014;24:143-53.

4. Fernández Sánchez FJ, Blanca Gómez M, Jerez Domínguez J, Rodríguez Fernández F, Martín Casañez E. Reacciones cutáneas graves producidas por fármacos: eritema exudativo multiforme, síndrome de Lyell, síndrome de hipersensibilidad a fármacos. In: Peláez Hernández A, Dávila González IJ, Editors. Tratado de Alergología II. Majadahonda (Madrid). Ergon, 2007; 1515-24.

5. Doña I, Blanca-Lopez N, Torres MJ, Garcia-Campos J, GarciaNunez I, Gomez F, et al. Drug hypersensitivity reactions: response patterns, drug involved, and temporal variations in a large series of patients. J Investig Allergol Clin Immunol. 2012:22:363-71.

6. Lobera Labairu T, Padial Vilchez MA, Guerrero García MA, Audicana Berasategui MT, García Abujeta JL. Concentraciones de principios activos y excipientes empleados para la realización de pruebas cutáneas y epicutáneas. In: Dávila González IJ, Jáuregui Presa I, Olaguibel Rivera JM, Zubeldía Ortuño JM, Editors. Tratado de Alergología IV. Majadahonda (Madrid). Ergon, 2016; 1679-86.

7. Pérez-Alzate D, Cornejo-García JA, Pérez-Sánchez N, Andreu I, García-Moral A, Agúndez JA, et al. Immediate Reactions to More Than 1 NSAID Must Not Be Considered CrossHypersensitivity Unless Tolerance to ASA Is Verified. J Invest Allergol Clin Immunol. 2017;27(1):32-9.

8. Himly M, Jahn-Schmid B, Pittertschatscher K, Bohle B, Grubmayr K, Ferreira F, et al. IgE-mediated immediate-type hypersensitivity to the pyrazolone drug propyphenazone. J Allergy Clin Immunol. 2003;111:882-8.

9. Mahboob A, Haroon TS. Drugs causing fixed eruptions: a study of 450 cases. Int J Dermatol. 1998;37:833-8.

- Manuscript received March 25, 2020; accepted for publication June 30, 2020.

Marta Reguero Capilla

Department of Allergology

University Hospital "Virgen del Rocío"

C/ Manuel Siurot

41013 Sevilla, Spain

E-mail: Martareguerocapilla1993@gmail.com 